\title{
Alcohol patterns and their relation to social climate in student residence halls-A multilevel analysis
}

\author{
H. Ståhlbrandt ${ }^{*}$, K. O. Johnsson, M. Berglund \\ Clinical Alcohol Research, Malmö, Sweden; ${ }^{*}$ Corresponding Author: henrietta.stahlbrandt@,med.lu.se
}

Received 4 March 2012; revised 18 April 2012; accepted 20 May 2012

\begin{abstract}
Background: Studies indicate that the social climate of students' living situation, plays a role in the drinking habits of those students. Aims: To investigate the social climate of students living in residence halls in Sweden, and how this corresponds to the students' alcohol habits. Methods: Baseline data from a randomised controlled trial performed at university halls of residence was used. Instruments included a Residence Hall Climate scale (measuring the environmental climate in residence halls), AUDIT (Alcohol Use Disorders Identification Test), SIP (Short Index of Problems) and self-reported eBAC (estimated Blood Alcohol Level). Multilevel modelling was used to include the possible effects of residence hall and residence hall cluster. Results: Residence halls with high scores for Distance and Expressiveness also had significantly higher alcohol measure scores. Closeness values had no impact on alcohol measurements. Most of the variance of the alcohol outcome measurements was found at individual student level, but significant variance was also found at residence hall level. Conclusions: This study implies that the environment of the residence halls is a factor in the students' alcohol habits. Changing the social climate might impact the way the students drink.
\end{abstract}

Keywords: Student Residence Hall; Emotional Climate; University Students; Drinking Patterns

\section{BACKGROUND AND AIM}

\subsection{Swedish Halls of Residence}

The close social interaction is one of the distinguishing characteristics of university residence hall accommodation. Few other living arrangements have conditions and prerequisites allowing the students to interact with each other as frequently as needed to create and maintain a unique and uniform social climate. It seems that the living arrangements for the college students can be both a moderator and mediator of the students' alcohol consumption: in a literature review, Jackson [1] showed that students with high-risk alcohol behaviour select residence halls and Greek houses, and that the living arrangements themselves have an additional influence on drinking behaviour.

The living arrangement influence is multi-factorial, ranging from higher perceived drinking norms and higher positive alcohol expectancies to environmental and cultural factors [2].

In addition to the residence halls and Greek houses, individual personalities seem to influence Greek house and alcohol involvement. Kahler, Read, Wood, \& Palfai [3] showed significant relationships between impulsive, sensation-seeking personality traits and Greek house involvement. In a review, Baer [4] states that students who are impulsive and have sensation-seeking personalities consume more alcohol than other students.

The environmental and social climates also play a role in this. Oostveen, Knibbe \& de Vries [5] showed that the social norm of family and peers and the importance of socialising and modelling are the most important factors in predicting heavy drinking in young adults.

\subsection{Social Climate Measurements}

Several different instruments have been used to measure social climate. Moos and his collaborators in the 1970s were the first to measure the social climate. Various Environmental Scales (Work, University Residence and Group) were constructed, using mostly interpersonal dimensions [6]. The University Residence Environmental Scale (URES) assesses the social climate of university students in three dimensions: relationships, personal growth or goal orientation, and system maintenance and change [7]. There is no Swedish version of URES.

In the 1980s, a Swedish Family Climate scale was created, measuring four different interpersonal dimensions (Closeness, Distance, Chaos and Expressiveness). This scale has been widely used in Sweden in a diversity 
of settings, including upper secondary school students, normal families, relatives to alcoholics and substance misusers [8-10].

\subsection{Social Climate and Alcohol Patterns}

Although the social climate of university residence halls is an important factor influencing student behaviour and perceptions, few studies have simultaneously investigated the correlation between, on the one hand, environmental and social influence and, on the other, alcohol use and college drinking.

Larimer, Irvine, Kilmer, \& Marlatt [11] showed that members of fraternities with a reputation for high alcohol consumption viewed the house members as more popular, better looking and wealthier-but less friendly - than students living in houses with a reputation for average or low alcohol consumption. Holle [12] looked at environment and alcohol use in fraternity houses, using Moos' URES. He showed that low-drinking fraternity houses perceived significantly more academic achievement, intellectuality and student influence than the high-drinking groups.

Carson, Barling, \& Turner [13] studied 96 Canadian students living in student houses off-campus. The results show that students living in houses with higher-alcohol climates also reported higher alcohol consumption. However, no significant relationships were found between house-level alcohol climate and house cohesion. No climate other than alcohol climate was measured.

Few studies have investigated the direct relationship between alcohol consumption patterns of college students and the social climate of their living quarters. No such Swedish studies have been published previously. This paper reports the findings on social climate of the Swedish residence halls and its correlation to the students' alcohol drinking patterns, as part of a larger alco- hol intervention study reported previously [14].

\subsection{Aim}

The aim is to investigate how the social climate will influence the alcohol pattern of the students.

\section{MATERIALS AND METHODS}

The study was initiated in the autumn of 2000 at Lund University, Sweden. The mean age of freshmen in Lund was 21.3 years old, and $45 \%$ of the freshmen were male [15]. In Sweden, freshmen usually begin by living in residence halls and then move out, but students are entitled to stay in residence halls throughout their period of study. As a consequence of this, most students in the residence halls are undergraduates, but may also include graduate students. All residence halls in this study are of mixed gender. There is no campus at the university, and the residence halls are scattered around the town in wider groups of residence hall communities (called Sparta, Delphi, etc.; called residence hall communities in this article). The characteristics of the residence halls visited can be seen in Table 1. In Sweden, there are no Greek houses, but it has previously been shown that the alcohol consumption in the Swedish halls of residence have more similarities to American Greek houses than American residence halls [14].

Research staff visited all 271 residence halls belonging to the university. Two hundred and forty of those were interested in participation when given a brief explanation of the study, and the remaining 31 residence halls did not accept inclusion at the initial meeting. No further contacts were initiated with those 31 halls. This first visit to the residence hall was a very brief one, to briefly explain the study and to decide on a date for a second visit to provide further information. On the second visit, the

Table 1. Characteristics of the residence halls visited.

\begin{tabular}{|c|c|c|c|c|c|c|}
\hline $\begin{array}{l}\text { Residence hall } \\
\text { community name }\end{array}$ & $\begin{array}{l}\text { Number of residence } \\
\text { halls visited }\end{array}$ & $\begin{array}{l}\text { Mean number of } \\
\text { students per } \\
\text { residence hall } \\
\text { visited }(\mathrm{n})\end{array}$ & $\begin{array}{c}\text { Mean number of } \\
\text { students per residence } \\
\text { hall completing } \\
\text { questionnaire (no } \pm \text { s.d.) }\end{array}$ & $\begin{array}{c}\text { Mean age } \\
\text { (years } \pm \text { s.d.) }\end{array}$ & $\begin{array}{l}\text { Gender } \\
(\% \text { male })\end{array}$ & $\begin{array}{l}\text { Mean AUDIT score } \\
\quad(\text { mean } \pm \text { s.d. })\end{array}$ \\
\hline Delphi & 79 & 10.7 & $7.0 \pm 2.9$ & $23.7 \pm 5.8$ & $71 \%$ & $9.4 \pm 5.3$ \\
\hline Kämnärsrätten & 8 & 12 & $7.2 \pm 1.4$ & $22.8 \pm 1.8$ & $64 \%$ & $9.1 \pm 4.4$ \\
\hline Parentesen & 31 & 10.2 & $5.1 \pm 2.2$ & $23.6 \pm 2.2$ & $55 \%$ & $9.8 \pm 5.0$ \\
\hline Sparta & 38 & 12.8 & $7.5 \pm 2.6$ & $23.9 \pm 3.1$ & $71 \%$ & $9.1 \pm 4.9$ \\
\hline Tomegapsgården & 2 & 9 & $6.2 \pm 1.0$ & $24.3 \pm 2.3$ & $50 \%$ & $7.8 \pm 2.7$ \\
\hline Ulrikedal & 40 & 8.5 & $6.2 \pm 2.4$ & $23.4 \pm 2.6$ & $58 \%$ & $10.4 \pm 5.1$ \\
\hline Vildanden & 33 & 12.3 & $7.5 \pm 2.8$ & $22.8 \pm 2.2$ & $58 \%$ & $9.4 \pm 5.4$ \\
\hline Total & 231 & 10.8 & $6.8 \pm 2.7$ & $23.5 \pm 3.9$ & $64 \%$ & $9.5 \pm 5.1$ \\
\hline
\end{tabular}


content and purpose of the study were described in greater depth, and students signed a written consent form. A survey was distributed, and this baseline survey forms the basis of the data and analyses in this article. Inclusion criteria included acceptance from over $50 \%$ of the residence hall inhabitants in each hall. Nine halls of residence were excluded in this stage due to technical reasons, leaving 231 halls to be included in the main study. This sub-analysis involved 154 halls of residence (see Section 2.2 analyses).

The study has been approved by the Ethics Committee at Lund University.

\subsection{Sample}

231 residence halls (1388 students) participated in the study at baseline. Of those, 154 residence halls (1101 students) had five or more students participating. All of them had completed AUDIT and Residence Hall Climate. 1017 students $(92.3 \%)$ completed the SIP questionnaire, $927(84.2 \%)$ the eBAC questions. Of all students included in this analysis, $65.0 \%$ were male, and $35.0 \%$ were female. The mean male age was $(23.8 \pm 4.9)$ years, and the mean female age was $(23.0 \pm 2.6)$ years.

\subsection{Instruments}

Five of the instruments in the survey are considered in this article.

Residence hall climate is derived from the Family Climate scale [8], and consists of a list of 85 words; the respondents underline the ones that apply to the measured climate. It is a self-reporting instrument developed to measure family climate in four dimensions, identified by factor analysis: Closeness (28 words, such as harmony, warmth and security), Distance (11 words: intolerance, indifference, bad, coolness, discontent, meaningless, ruthlessness, insensitive, affected, strenuous, aggressive), Expressiveness (6 words: spontaneity, childishness, liveliness, explosive, rush, wild) and Chaos (6 words: confusion, nervousness, instability, insecure, division, restlessness). An index is calculated for each factor, and a factor score of 1 indicates that the same proportion of words has been marked on that subscale as on the whole scale. Similarly, numbers above 1 indicate that proportionately more words have been marked on that subscale than on the whole scale. The heading of the instrument was changed to "Residence hall climate" in the questionnaires, in order to prevent the students being confused about which climate they were to rate.

The instrument is used on a daily basis in practical work in Sweden. It is validated through comparison to other similar instruments and through comparison with 20 studies that used the instrument [10]. The test-retest reliability is 0.95 for three weeks and 0.89 for five months [8]. The Family Climate instrument scales correlate to the Swedish version of Moos's Family Environment Scale $[9,10]$. Closeness correlates positively to the positive subscales of the Family Environment Scale, whereas Distance, Expressiveness and Chaos correlate negatively to those subscales. Closeness is inversely correlated to the more negative subscales of the Family Environment Scale, whereas Distance, Expressiveness and Chaos are directly correlated. Thus, Closeness is regarded as a positive attribute, whereas the other three subscales (Distance, Expressiveness and Chaos) are regarded as subscales representing a negative social environment.

AUDIT (Alcohol Use Disorders Identification Test) consists of ten questions about alcohol consumption, dependence and harm, and has been increasingly used since its development by the World Health Organization in the 1980s [16]. The Swedish translation of the test was used [17], where one standard drink is defined as the equivalent of $12 \mathrm{~g}$ alcohol. Cronbach's $\alpha$ was found to be 0.81 in a previous study using the Swedish AUDIT [18]. Cronbach's $\alpha$ in this study is 0.84 .

SIP (Short Index of Problems) was developed by Miller [19]. It assesses a sample of possible alcohol problems. The brief version was used, translated to Swedish by the Clinical Alcohol Research group at Lund University, and has previously been used in Swedish alcohol prevention studies [20]. It has 15 questions and a maximum score of 45. Miller et al. [19] obtained an internal consistency of 0.81 and, in this study, Cronbach's $\alpha$ is 0.91 . At-risk AUDIT levels were defined as an AUDIT score of $\geq 8$ for males and $\geq 4$ for females [20].

$e B A C$ (estimated blood alcohol concentration) is a retrospective self-assessment questionnaire where the student provides data about the most recent pleasant drinking occasion (number of drinks, length of drinking session, gender and weight). The use of the word "pleasant" was chosen to avoid negative social reactions, and has been used in previous Swedish alcohol prevention studies $[21,22]$. By asking about a pleasant drinking occasion, it is considered to measure a typical optimal drinking occasion rather than a peak drinking occasion. Based on this data, the BAC was estimated as a percentage [23], adjusted for Swedish weight units and alcohol content of drink by volume. eBAC is reported in \%o, as is customary in Sweden.

\subsection{Analyses}

The mean number of participating students per residence hall was 6.8. The mean number of students living in each residence hall was 10.8. For all analyses, only residence halls where five or more students had answered the baseline questionnaire were included ( $\mathrm{n}=$ 
154). The Residence Hall Climate scales are used on a contextual level, and halls where fewer students participated were judged not to be representative in this analysis. Halls where six or more persons answered the questionnaire yielded somewhat higher correlations, but this meant a loss of another 41 residence halls $(\mathrm{n}=113)$. Consequently, this was not used in the analyses.

Population characteristics were analysed using means and standard deviations. Residence Hall Climate distribution was described using means, standard deviations and skewness. Correlations between the different Residence Hall Climate subscales were examined using Spearman correlations.

For the main analyses, multilevel modelling (MLM) was used (see Figure 1 for model; [24,25]).

First-level units were the individual students. Second-level units were the residence halls in which the students resided. The third level of analysis was the residence hall community. Residence halls and residence hall communities were marked as random effects, in order to assess the variability among individuals within residence halls, among residence halls and among residence hall communities. AUDIT, SIP and eBAC were analysed as dependent variables. Intercepts were used for both fixed and random effects. Age and gender were used as fixed factors in all analyses. Mean Residence Hall Climate scores across the residence hall were used

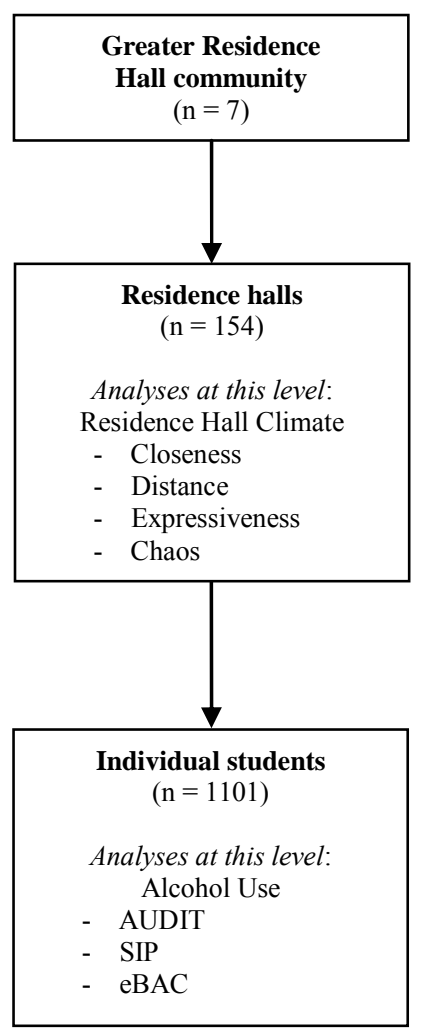

Figure 1. Study analysis model. throughout the analyses, as Residence Hall Climate was regarded as a contextual factor. Due to the nature of the Residence Hall Climate scale, quartiles produce more understandable results than logarithmically transforming the scales. The reference quartiles were the highest Closeness quartile and the lowest of Distance, Expressiveness and Chaos, in order to make comparisons comprehensible. The reference quartiles thus represent the most positive climate possible within the residence halls.

The analyses were carried out in SPSS MIXED MODELS, version 15.

\subsection{Missing Data}

Data missing from the students' AUDIT and SIP questionnaires was supplemented manually, using completed questionnaires as guidelines, in a regression imputation manner [26]. If more than $20 \%$ of the questions within the same questionnaire were left unanswered, the questionnaire was regarded as incomplete and was omitted from the analysis. Questionnaires for eBAC that lacked data were regarded as incomplete and were excluded from the analysis. The Residence Hall Climate questionnaire was of such a nature that there was no missing data.

\section{RESULTS}

\subsection{Results on Individual Level}

For the men, the mean ( \pm s.d.) AUDIT score was 10.3 \pm 5.6 , SIP $3.0 \pm 3.7$ and $\mathrm{BAC} 1.07 \pm 0.73$. For women, the mean $( \pm$ s.d.) scores were $8.1 \pm 4.7$ for AUDIT, $2.5 \pm$ 3.3 for SIP and $1.09 \pm 0.74$ for eBAC. AUDIT and SIP scores were significantly different at the 0.05 level between the genders. eBAC scores were not significantly different.

\subsection{Residence Hall Climate}

The mean Closeness index was 1.95 , with a standard deviation of 0.45. The mean Distance index was 0.20 (s.d. 0.22). The mean Expressiveness index was 1.05 (s.d. 0.87). The mean Chaos index was $0.30(0.42)$.

Closeness quartiles were significantly correlated to Distance quartiles (Spearman $=0.32$ ), Expressiveness quartiles (Spearman $=0.28)$ and Chaos quartiles (Spearman $=0.28$ ). Distance quartiles and Expressiveness quartiles were inversely correlated (Spearman $=-0.15$ ), and the correlation between Distance and Chaos was 0.27. Expressiveness and Chaos were not correlated (Spear$\operatorname{man}=-0.01)$.

\subsection{Residence Hall Climate and AUDIT}

In AUDIT, only gender and Expressiveness produced significant changes, on the general level. Looking at 
the individual quartiles of the Residence Hall Climate, Closeness was not significant (see Table 2). Belonging to the highest quartile of Distance, the two highest quartiles of Expressiveness, or the second highest quartiles of Chaos significantly increased the AUDIT scores compared to the reference quartiles (see Table 2 for numbers).

The main variance was between the individuals in the residence halls $(23.14, \mathrm{p}<0.001,95 \%$ CI 21.0, 25.5), with some variance between the residence halls $(1.74, \mathrm{p}$ $=0.01,95 \%$ CI $0.81,3.74)$, but none between the greater residence hall communities $(\mathrm{p}=0.41)$.

\subsection{Residence Hall Climate and SIP}

As for Short Index of Problems, SIP, the highest Distance quartile and the highest Expressiveness quartile had significantly higher SIP scores than their lowest counterparts (for numbers, see Table 2). The dimensions Closeness and Chaos did not produce significant results.

The variance of SIP scores was within residence hall level $(11.45, \mathrm{p}<0.0001,95 \%$ CI $10.4,12.7)$ and between residence hall level $(1.11, \mathrm{p}<0.01,95 \%$ CI $0.57,2.17)$, but not at residence hall community level $(p=0.23)$.

\subsection{Residence Hall Climate and eBAC}

In the eBAC model, only Distance had a general effect that reached the 0.05 level of significance. The highest quartiles of Distance and Expressiveness significantly differed from their lowest reference quartiles (see Table 2). The variance in eBAC was primarily within residence halls (estimate $0.51, \mathrm{p}<0.0001,95 \%$ CI $0.46,0.57$ ). No variance of significance could be seen between residence halls $(\mathrm{p}=0.14)$ or between residence hall communities $(\mathrm{p}=0.55)$.

Table 2. The influence of age, gender, residence hall climate, residence hall and residence hall community on AUDIT, SIP and eBAC.

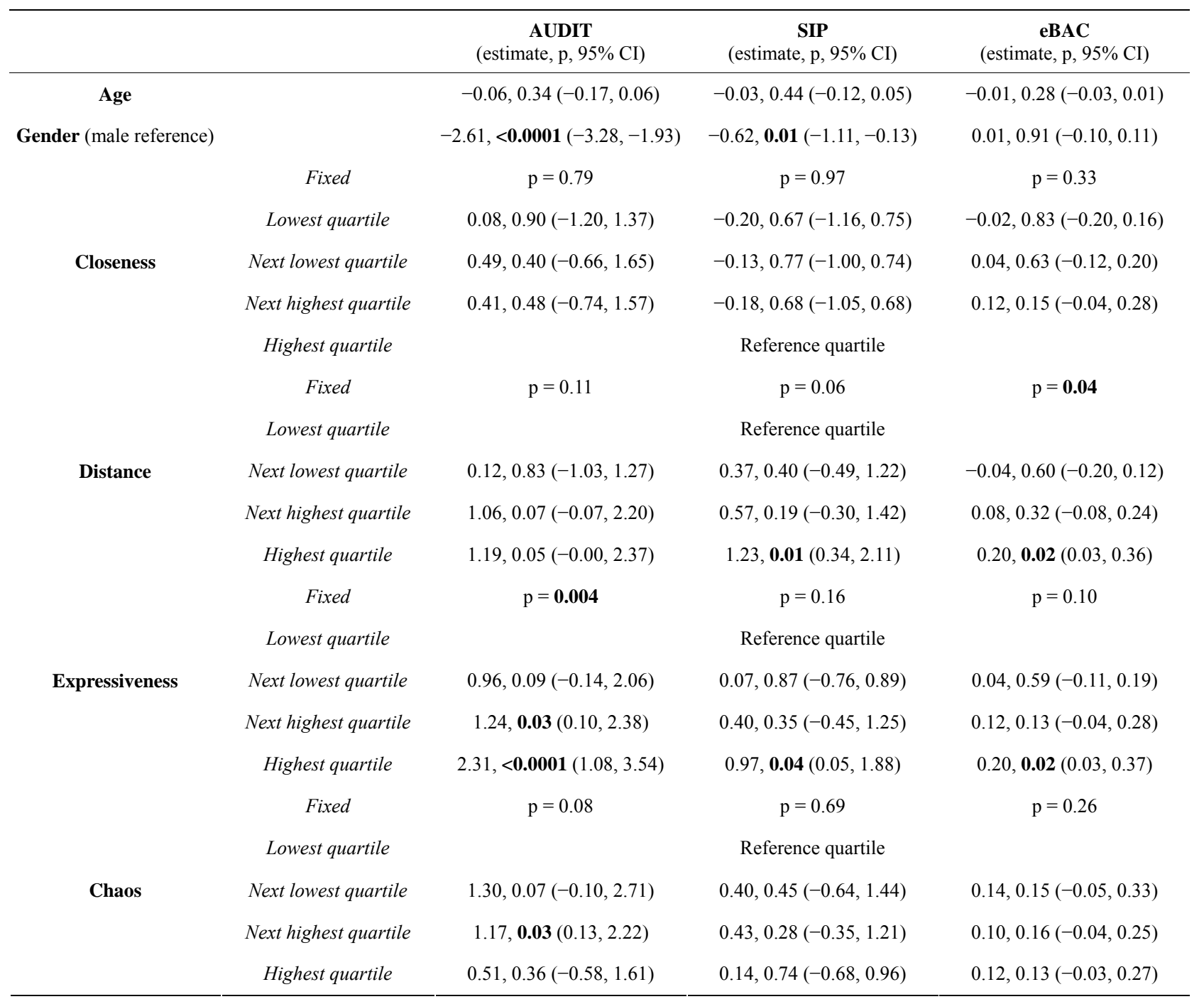




\section{DISCUSSION}

The main finding was that the residence halls with the character of high Distance or high Expressiveness had higher AUDIT, SIP and eBAC scores than halls with lower Distance or Expressiveness, indicating a more problematic approach to drinking. It is of interest to see that Closeness, the one Residence Hall Climate factor that can be regarded as a positive one, had no influence on the drinking habits of the residence hall students. Compared to a literature review of Residence Hall Climate studies including eleven non-clinical studies, ten psychiatric health care studies, five somatic health care studies and five social services studies [10], the resident hall student population seems to be a well-functioning group, although the general drinking level is high within this population.

Another finding was that gender relates to AUDIT and SIP scores, but not eBAC. This was expected, since gender is part of the equation for calculating eBAC levels [23]. AUDIT, SIP or eBAC were not influenced by the age of the students. This was somewhat surprising, since other studies have shown differences in drinking patterns at different ages [27-29]. It might be that age is of less importance when living in such a close environment as the residence hall, and that the pattern of alcohol consumption is more affected by the individuals in the same hall than by other persons in the same age group.

The AUDIT levels of $10.3 \pm 5.3$ for men and $8.1 \pm 4.7$ for women were well above the limits for at-risk alcohol consumption, as defined by the NIAAA [20]. They were, however, quite similar to the AUDIT levels found by Kypri et al. [28] in students living in residence halls in New Zealand: $10.9 \pm 7.6$ and $7.6 \pm 5.9$ (mean \pm s.d.) for men and women respectively. Also, students in halls of residence tend to drink more than the average university student, and students at the University of Lund have amongst the highest levels of alcohol consumption of Swedish university students [27]. This may be attributed to the classic university atmosphere in the town, which is largely dominated by students.

Strengths of the study are first and foremost the large number of students included, without any monetary incentives or extended preparation. In reality, the mean number of students per residence hall was less than 10.8 , since some residence hall rooms are usually emptyunfortunately, we do not know how many were empty at the time of the study. This is one of the very few studies focusing on alcohol habits and residence hall students, including residence hall level in the analysis. Inclusion of a climate scale adds to the explanatory value of the students' drinking habits.

Weaknesses include the possible bias of using only self-reporting instruments. What effect this has on the study is impossible to tell. Since high alcohol consumption is not looked upon negatively in this population, it cannot be automatically assumed that the actual consumption is higher than the self-reported one. The research literature remains divided on the accuracy of college students' estimates of their drinking [29,30]. Furthermore, the students were asked to report their previous pleasant drinking occasion, which might cause bias in the reporting. The studied population had a higher ratio of men to women than the university as a whole. By carrying out gender-separate analyses as well as including the gender in all analyses, care has been taken to minimise this problem. However, it cannot be excluded that this male majority influences the reported Residence Hall Climate.

An interesting idea would be to select residence halls based on their environmental climate, or at least take this into consideration, when planning alcohol interventions. Reducing the students' feelings of Distance and Expressiveness in their living arrangements might also decrease the more risky alcohol habits of those students. However, it cannot be excluded that the students drink to cope with a negative residence hall social climate, or that there is a positive self-selection into those particular residence halls when choosing where to live, and further research is needed to clarify these processes. The question of causality cannot be answered in this study.

\section{CONCLUSION}

The findings in this study suggest that alcohol habits (consumption and alcohol-related problems) might be connected to the more negative aspects of the environmental climate of the students living quarters, in this study the halls of residence at a Swedish university. Further research is needed to understand this relationship in more detail.

\section{REFERENCES}

[1] Jackson, K.M., Sher, K.J. and Park, A. (2005) Drinking among college students - Consumption and consequences. In: Galanter, M., Ed., Recent Developments in Alcoholism: Research on Alcohol Problems in Adolescents and Young Adults Volume XVII, Kluwer Academic/Plenum Publishers, New York, 85-117.

[2] Larimer, M.E., Turner, A.P., Mallett, K.A. and Geisner, I.M. (2004) Predicting drinking behavior and alcohol-related problems among fraternity and sorority members: Examining the role of descriptive and injunctive norms. Psychology of Addictive Behaviors, 18, 203-212. doi:10.1037/0893-164X.18.3.203

[3] Kahler, C.W., Read, J.P., Wood, M.D. and Palfai, T.P. (2003) Social environmental selection as a mediator of gender, ethnic, and personality effects on college student drinking. Psychology of Addictive Behaviors, 17, 226- 


\section{4. doi:10.1037/0893-164X.17.3.226}

[4] Baer, J.S. (2002) Student factors: Understanding individual variation in college drinking. Journal of Studies on Alcohol and Drugs, 14, 40-53.

[5] Oostveen, T., Knibbe, R. and de Vries, H. (1996) Social influences on young adults' alcohol consumption: Norms, modeling, pressure, socializing, and conformity. Addictive Behaviors, 21, 187-197. doi:10.1016/0306-4603(95)00052-6

[6] Salter, D.W. (2003) A generalizability study of salter environmental type assessment scores by social climate domain. Measurement and Evaluation in Counseling and Development, 36, 130-139.

[7] Moos, R.H. (1978) Social environments of university student living groups: Architectural and organizational correlates. Environment and Behavior, 10, 109-126. doi: $10.1177 / 0013916578101005$

[8] Hansson, K. (1989) Family Climate. An adjective list for family diagnostics. Psykologi i Tillämpning, 7, 1-39.

[9] Hansson, K. (1992) Family in society. Translation and work on a self-defence instrument constructed by Moos \& Moos. (Vol. 2). Lund University, Lund.

[10] Söderlind, M. and Johnsson, B. (2004) Family climate, a validation. Lund University, Lund.

[11] Larimer, M.E., Irvine, D.L., Kilmer, J.R. and Marlatt, G.A. (1997) College drinking and the Greek system: Examining the role of perceived norms for high-risk behavior. Journal of College Student Development, 38, 587-598.

[12] Holle, T.T. (1986) Environmental study of alcohol use in fraternity houses. Campus Ecologist, 3. http://www.campusecologist.com/1986/01/05/volume-ivnumber-3-1986/

[13] Carson, J., Barling, J. and Turner, N. (2007) Group alcohol climate, alcohol consumption, and student performance. Group Dynamics: Theory, Research and Practice, 11, 31-41. doi:10.1037/1089-2699.11.1.31

[14] Stahlbrandt, H., Andersson, C., Johnsson, K.O., Tollison, S.J., Berglund, M. and Larimer, M.E. (2008) Cross-cultural patterns in college student drinking and its consequences-A comparison between the USA and Sweden. Alcohol and Alcoholism, 43, 698-705. doi:10.1093/alcalc/agn055

[15] Swedish National Agency for Higher Education (2005) National monitoring database, 2000. http://nu-prod.hsv.se/

[16] Saunders, J.B., Aasland, O.G., Babor, T.F., de la Fuente, J.R. and Grant, M. (1993) Development of the alcohol use disorders identification test (AUDIT): WHO collaborative project on early detection of persons with harmful alcohol consumption-II. Addiction, 88, 791-804. doi:10.1111/j.1360-0443.1993.tb02093.x

[17] Bergman, H., Källmén, H., Rydberg, U. and Sandahl, C. (1998) A 10-item questionnaire identifying alcohol problems was tested psychometraically at a psychiatric emergency ward. Läkartidningen, 95, 4731-4737.

[18] Bergman, H. and Källmén, H. (2000) Alcohol use among
Swedes as assessed by the alcohol use disorders identification test (AUDIT): A psychometric study. Läkartidningen, 97, 2078-2084.

[19] Miller, W.R., Tonigan, J.S. and Longabaugh, R. (1995) The drinker inventory of consequences (DrInC): An instrument for assessing adverse consequences of alcohol abuse. (DHHS publication No. 95-3911), National Institute on Alcohol Abuse and Alcoholism, Rockville.

[20] NIH (National Institute of Health) (2005) Helping patients who drink too much a clinician's guide. National Institute on Alcohol Abuse and Alcoholism.

http://pubs.niaaa.nih.gov/publications/practitioner/clinicia nsguide2005/clinicians guide.htm

[21] Hansson, H., Rundberg, J., Zetterlind, U., Johnsson, K.O. and Berglund, M. (2006) An intervention program for university students who have parents with alcohol problems: A randomized controlled trial. Alcohol and Alcoholism, 41, 655-663. doi:10.1093/alcalc/agl057

[22] Andersson, C., Johnsson, K.O., Berglund, M. and Ojehagen, A. (2007) Alcohol involvement in Swedish university freshmen related to gender, age, serious relationship and family history of alcohol problems. Alcohol and Alcoholism, 42, 448-455. doi:10.1093/alcalc/agm008

[23] Dimeff, L.A., Baer, J. and Kivlahan, D.R. (1999) Brief alcohol screening and intervention for college students (BASICS). A harm reduction approach. The Guilford Press, New York.

[24] Peugh, J.L. and Enders, C.K. (2005) Using the SPSS mixed procedure to fit cross-sectional and longitudinal multilevel models. Educational and Psychological Measurement, 65, 717-741. doi:10.1177/0013164405278558

[25] Tabachinick, B.G. and Fidell, L.S. (2007) Using multivariate statistics. 5th Edition, Pearson Education, Inc., Boston.

[26] Wood, A.M., White, I.R. and Thompson, S.G. (2004) Are missing outcome data adequately handled? A review of published randomized controlled trials in major medical journals. Clinical Trials, 1, 368-376. doi:10.1191/1740774504cn032oa

[27] Bullock, S. (2004) Alcohol, drugs and student lifestyle: A study of the attitudes, beliefs and use of alcohol and drugs among Swedish University Students. SoRAD—Research report No. 21. SoRAD Report Series, Stockholm.

[28] Kypri, K., Langley, J.D., McGee, R., Saunders, J.B. and Williams, S. (2002) High prevalence, persistent hazardous drinking among New Zealand tertiary students. Alcohol and Alcoholism, 37, 457-464. doi:10.1093/alcalc/37.5.457

[29] Winters, K.C., Stinchfield, R.D., Henly, G.A. and Schwartz, R.H. (1990) Validity of adolescent self-report of alcohol and other drug involvement. International Journal of the Addictions, 25, 1379-1395.

[30] Clapp, J.D., Min, J.W., Shillington, A.M., Reed, M.B., Lange, J.E. and Holmes, M.R. (2006) Environmental and individual predictors of error in field estimates of blood alcohol concentration: A multilevel analysis. Journal of Studies on Alcohol and Drugs, 67, 620-627. 